\title{
Assessment of a national voucher scheme to deliver insecticide-treated mosquito nets to pregnant women
}

\author{
Tanya Marchant PhD, David Schellenberg MRCP, Rose Nathan PhD, \\ Joanna Armstrong-Schellenberg PhD, Hadji Mponda MSc, Caroline Jones PhD, \\ Yovitha Sedekia BSc, Jane Bruce MSc, Kara Hanson ScD
}

Previously published at www.cmaj.ca

\section{ABSTRACT}

Background: The benefits of a health-related intervention may be compromised by the challenges of delivering the intervention on a large scale. We analyzed the process involved in the Tanzania National Voucher Scheme, a system for delivering insecticide-treated mosquito nets to pregnant women. We aimed to identify potential ways to equitably improve overall coverage of the intervention.

Methods: We defined five steps in the process. We collected data from a multistage cluster survey of nationally representative households conducted in 2007 across 21 districts in Tanzania. Using these data, we multiplied the rate of success of each step cumulatively to estimate the overall success of the system.

Results: The rate of coverage for use of insecticide-treated nets among pregnant women was $23 \%$ ( $95 \%$ confidence interval [CI] 19\%-27\%). We observed large differences in coverage by socio-economic status, from $7 \%$ (95\% Cl $4 \%-$ $13 \%$ ) among participants in the poorest households to $48 \%(95 \% \mathrm{Cl} 38 \%-59 \%)$ among those in the richest households. The rate of success of each step in the process was high $(60 \%-98 \%)$. However, the cumulative rate of success for the process as a whole was low $(30 \%)$. The largest and most inequitable reduction in coverage occurred in the step involving treatment of nets with insecticide.

Interpretation: The cumulative effect of modest attrition at several steps in the process substantially diminished the overall rate of coverage for all women, but most markedly among the poorest participants. Analysis of the process suggests that delivery of nets treated with long-lasting insecticide rather than untreated nets packaged with an insecticide-treatment kit could result in an improvement in coverage of 22 percentage points, from $30 \%$ to $52 \%$.

$O$ ystems designed to deliver health-related interventions on a large scale require a number of operational steps to reach targeted groups. Some people will not be reached at each step because of attrition, which creates a staircase effect of diminishing effectiveness at the population level. ${ }^{1,2}$ This cumulative effect may be further pronounced among people in poor households, because they may be more likely than those in wealthier households to drop out at each step. ${ }^{3}$

We investigated the impact of reductions in coverage on the effectiveness of a national multistep system in Tanzania to deliver insecticide-treated mosquito nets to pregnant women. The use of such nets has been shown to reduce childhood mortality by $17 \%$ across different African settings. ${ }^{4}$ When used by pregnant women, these nets have been associated with a reduction of $38 \%$ in the incidence of maternal malaria parasitemia, of $47 \%$ in the incidence of severe malarial anemia and of $28 \%$ in the prevalence of infants with low birth weights. ${ }^{5}$

All socio-economic groups are susceptible to malaria. ${ }^{6}$ However, there can be large socio-economic inequities in knowledge of the risks associated with infection, in access to prevention and treatment, and in ability to pay for prevention and treatment. ${ }^{7}$ Over the last 10 years, political commitment to achieve high and equitable coverage for the delivery of insecticide-treated nets has grown. Many countries in sub-Saharan Africa have committed to the target set at a meeting in Abuja, Nigeria, in 2000 to increase coverage among children and pregnant women to at least $60 \%$, a target recently increased to $80 \%$ by $2010 .{ }^{8}$ However, progress has been slow: coverage among children under five years of age in malaria-endemic regions of Africa was estimated to be less than $20 \%$ in $2007 .{ }^{9}$

Since 2006, Tanzania has implemented a discount voucher system on a national level to deliver insecticide-treated nets to pregnant women. Although relatively simple, the process involves a sequence of five steps that include the woman attending an antenatal clinic, obtaining a voucher there, using the voucher to buy a mosquito net packaged with insecticide, treating the net with the insecticide and, finally, using the net. Each step depends on the success of the previous one. At each point, a pregnant woman may drop out of the process and end up unprotected. If we assume hypothetically that $90 \%$ of women are reached at each step, the coverage would be only $59 \%(100 \times 0.9 \times 0.9 \times 0.9 \times 0.9 \times 0.9=59)$. Furthermore

From the London School of Hygiene and Tropical Medicine (Marchant, Schellenberg, Armstrong-Schellenberg, Jones, Bruce, Hanson), London, UK and the Ifakara Health Institute (Nathan, Armstrong-Schellenberg, Mponda, Sedekia), Dar es Salaam, Tanzania

CMAJ 2010. DOI:10.1503/cmaj.090268 
there are likely to be socio-economic differences that give rise to an "equity gap" at each step.

We conducted this study to analyze the processes involved in the Tanzanian discount voucher system. Using survey data collected as part of the program for monitoring and evaluating the system, we calculated the cumulative success of the system for different socio-economic groups. We also explored opportunities to improve the system.

\section{Methods}

Tanzania, a country of 40 million people, is one of the poorest countries in the world, with a gross national income per capita of $\$ 400$ in 2007 . It has a high fertility rate (5.2 births per woman on average), high mortality (116 deaths per 1000 live births among children less than five years old) and a life expectancy at birth of 52 years. ${ }^{10}$ Malaria is endemic in most regions of the country and is the leading cause of outpatient morbidity and inpatient mortality among children.

The Tanzanian National Voucher Scheme is an innovative system that uses discount vouchers as a means of delivering insecticide-treated nets. Launched in 2004 and implemented at a national level since 2006, it targets pregnant women and infants by giving a voucher to pregnant women at their first antenatal visit. The women can use the voucher as partial payment toward the purchase of a net. The sequence of steps is described in detail in Appendix 1 (available at www.cmaj.ca /cgi/content/full/cmaj.090268/DC1). In brief, each woman must first attend an antenatal clinic, then be given a discount voucher, then use the voucher to buy a net, ensure that the purchased net is packaged with insecticide, use the insecticide to treat the new net and, finally, reach the desired outcome of sleeping under the treated net.

The Tanzanian voucher system represents one of the commitments made by the country's Ministry of Health and Social Welfare to reduce the burden of malaria. To maximize lessons learned from the approach, we developed and implemented a comprehensive program for monitoring and evaluating the system, in partnership with the National Malaria Control Programme. As part of the program, surveys of nationally representative households and linked health facilities have been conducted. ${ }^{11}$

\section{Household surveys}

Cluster surveys of nationally representative households were conducted in 2005, 2006 and 2007. Twenty-one of the 113 districts in mainland Tanzania (i.e., excluding Zanzibar) listed in the 2002 census were randomly selected. In each district, a random sample of 10 clusters of 30 households each was selected, for a total of 6300 households. Clusters were sampled in two stages: first, 10 wards within each district were selected with probability proportional to ward population. Within each chosen ward, one subvillage (kitongoji) was selected with the use of simple random sampling. Within each subvillage, 30 households were chosen by means of a modified version of the sampling scheme used by the World Health Organization in its Expanded Program on Immunization. This method ensures an equal chance of selection for all households where no formal sampling frame of households is available.
In each household, the consenting heads of the household and all women aged 15-49 years were interviewed; additional modules of the survey were used for women who had had a live birth in the preceding 12 months ("past pregnancies") and those who were pregnant at the time of the survey ("current pregnancies"). These two groups of women were selected because those with a past pregnancy could report on their experience during the entire pregnancy, and those in the other group could contribute information on the use of an insecticide-treated net on the night before the survey by currently pregnant women.

In this analysis, an insecticide-treated net refers to a mosquito net that has had insecticide applied to it in the 12 months before the survey or been treated with a long-lasting insecticide (i.e., one that binds to the fibre of the net and remains efficacious after numerous washes and over time).

The variables extracted from the survey data for our analysis are described in Appendix 2 (available at www.cmaj.ca /cgi/content/full/cmaj.090268/DC1).

\section{Socio-economic status}

An index of socio-economic status was constructed for each household on the basis of principal components of household indicators, including asset ownership, housing conditions and education level of the head of the household. ${ }^{12}$ This approach reflects relative socio-economic status of households and has been used to analyze inequities in the uptake of essential health services. ${ }^{13}$ The continuous variable representing the first principal component was divided into five quintiles of equal size, with the first quintile representing the poorest and the fifth quintile the richest. The distribution of household characteristics that were used to generate the socio-economic index for the group of women with a past pregnancy are shown in Appendix 3 (available at www.cmaj.ca/cgi/content /full/cmaj.090268/DC1), to illustrate the nature of the poverty in the different socio-economic groups.

\section{Analysis of the process}

We used data from the 2007 survey to analyze the five steps of the voucher system. First, we analyzed the survey indicators for each step by socio-economic status among women with a past pregnancy. We calculated the equity ratio (the ratio of coverage between the first and fifth quintile) to explore the equity gap between the poorest and richest women. Success at each step, and for each socio-economic group, was multiplied cumulatively to represent the overall success of the voucher system. Second, using the data for currently pregnant women, we compared the reported use of insecticide-treated nets on the night before the survey with the analysis of process. Finally, we estimated the hypothetical impact that changes in the voucher system might have on the coverage achieved by the system.

\section{Statistical analysis}

National estimates of the use of insecticide-treated nets were weighted according to district population in the 2002 Tanzania Population and Housing Census. We used the $\chi^{2}$ test for trend to test hypotheses concerning inequalities by socioeconomic status. 


\section{Results}

In $2007,1.5 \%$ of the 6300 sampled households refused to be interviewed; 6198 interviews of household members were completed across the 21 sampled districts. A total of 1327 women who had had a live birth in the 12 months before the survey were interviewed: $18 \%$ were in the first (poorest) socio-economic quintile, $25 \%$ in the second quintile, $20 \%$ in the third, $21 \%$ in the fourth and $17 \%$ in the fifth (richest) quintile. Information about all five steps of the process was available for 1320 of these 1327 women. A total of 707 women who were pregnant at the time of the survey were also interviewed: $20 \%$ in the first quintile, $24 \%$ in the second, $21 \%$ in the third, $19 \%$ in the fourth and $16 \%$ in the fifth quintile.

The proportion of women who completed each of the five steps in the process of the voucher system is shown in Table 1. The success rate for two of the steps - attending an antenatal clinic and purchasing a net packaged with insecticide was greater than $90 \%$. The overall rate of success of the remaining three steps was $60 \%-73 \%$. When disaggregated by socio-economic status, the poorest women were disadvantaged at every step. However, they were not significantly disadvantaged in the receipt of vouchers $(73 \%$ overall, equity ratio of $0.86, \chi^{2}$ test for trend $p=0.1$ ), or in the purchase of a net packaged with insecticide (95\% overall, equity ratio of $0.96, \chi^{2}$ test for trend $p=0.2$ ).
Applying the analysis of the process shows that overall attrition affected all of the women regardless of their socioeconomic status (Table 1). The cumulative success of the system was $30 \%$; that is, $70 \%$ of potential coverage was lost by the end of the process. Furthermore, considerable inequity was evident, given a cumulative rate of coverage of only $18 \%$ among the poorest women in the sample compared with $37 \%$ among the richest.

For comparison, the use of treated nets by currently pregnant women (insecticide-treated net coverage) is also shown in Table 1. Overall, $23 \%$ (95\% confidence interval [CI] 20\%$27 \%$ ) of pregnant women reported using a treated net on the night before the survey. A strongly significant, negative association between socio-economic status and coverage was evident: $7 \%$ coverage $(95 \%$ CI $4 \%-13 \%)$ among the poorest women and $48 \%$ coverage $(38 \%-59 \%)$ among the richest $\left(\chi^{2}\right.$ test for trend $p<0.01$ ).

A comparison of the cumulative success at each step of the system among the poorest women, the richest women and all women in the sample is shown in Figure 1. Across all three groups, the pattern of attrition was similar, with particularly large losses of participants observed at step 5, which involved the application of insecticide to the nets. If the need for participants to purchase and apply insecticide to the nets were eliminated from the process (i.e., effectively ending the process at step 3), the rates of success reflected in Figure 1 would have increased from $18 \%$ to $41 \%$ for the poorest

Table 1: Proportion of women who completed each of the five steps in the Tanzanian National Voucher Scheme for delivery of insecticide-treated mosquito nets to pregnant women, by socio-economic status

\begin{tabular}{|c|c|c|c|c|c|c|c|c|}
\hline \multirow[b]{2}{*}{ Step } & \multicolumn{6}{|c|}{ Socio-economic status, quintile; \% of women* } & \multirow[b]{2}{*}{$p$ value } & \multirow{2}{*}{$\begin{array}{c}\text { Equity } \\
\text { ratio: } \\
\text { Q1:Q5 }\end{array}$} \\
\hline & $\begin{array}{c}\mathrm{Q} 1 \\
n=232\end{array}$ & $\begin{array}{c}\mathrm{Q} 2 \\
n=326\end{array}$ & $\begin{array}{c}\text { Q3 } \\
n=260\end{array}$ & $\begin{array}{c}\mathrm{Q} 4 \\
n=273\end{array}$ & $\begin{array}{c}\text { Q5 } \\
n=229\end{array}$ & $\begin{array}{c}\text { All } \\
n=1320\end{array}$ & & \\
\hline $\begin{array}{l}\text { Women who had live birth in } \\
12 \text { months before surveyt§ }\end{array}$ & 232 & 326 & 260 & 273 & 229 & 1320 & & \\
\hline 1. Attended antenatal clinic§ & 94 & 98 & 99 & 99 & 99 & 98 & $<0.01$ & 0.95 \\
\hline 2. Received voucher§ & 67 & 73 & 72 & 72 & 78 & 73 & 0.16 & 0.86 \\
\hline 3. Redeemed voucher§ & 64 & 71 & 71 & 76 & 79 & 73 & $<0.01$ & 0.81 \\
\hline $\begin{array}{l}\text { 4. Ensure mosquito net is } \\
\text { packaged with insecticide§ }\end{array}$ & 89 & 94 & 97 & 99 & 93 & 95 & 0.25 & 0.96 \\
\hline $\begin{array}{l}\text { No. all nets bought using } \\
\text { voucher** }\end{array}$ & 176 & 323 & 365 & 362 & 280 & 1506 & & \\
\hline $\begin{array}{l}\text { 5. Effective treatment of } \\
\text { voucher nets** }\end{array}$ & 49 & 57 & 59 & 64 & 66 & 60 & $<0.01$ & 0.74 \\
\hline $\begin{array}{l}\text { Cumulative success of the } \\
\text { process }\end{array}$ & 18 & 27 & 29 & 34 & 37 & 30 & & 0.48 \\
\hline $\begin{array}{l}\text { No. all currently pregnant } \\
\text { womentt }\end{array}$ & 138 & 172 & 147 & 137 & 113 & 707 & & \\
\hline $\begin{array}{l}\text { Insecticide-treated net } \\
\text { use by currently pregnant } \\
\text { womentt, \% }(95 \% \mathrm{Cl})\end{array}$ & $\begin{array}{c}6.9 \\
(3.6-12.6)\end{array}$ & $\begin{array}{c}15.8 \\
(11.0-22.3)\end{array}$ & $\begin{array}{c}29.8 \\
(21.8-39.4)\end{array}$ & $\begin{array}{c}24.1 \\
(16.4-34.0)\end{array}$ & $\begin{array}{c}47.9 \\
(37.5-58.5)\end{array}$ & $\begin{array}{c}23.2 \\
(19.5-27.4)\end{array}$ & $<0.01$ & 0.14 \\
\hline
\end{tabular}

*Unless stated otherwise.

tThe denominator for steps $1-4$ is restricted to the numerator of each previous step.

$\S$ Estimates taken from household survey interviews with women who had a live birth in the 12 months prior to survey.

**Estimates taken from household heads report of net treatment status for all nets purchased using a net voucher.

††Estimates taken from household survey interviews with currently pregnant women reporting insecticide treated net use previous night. 


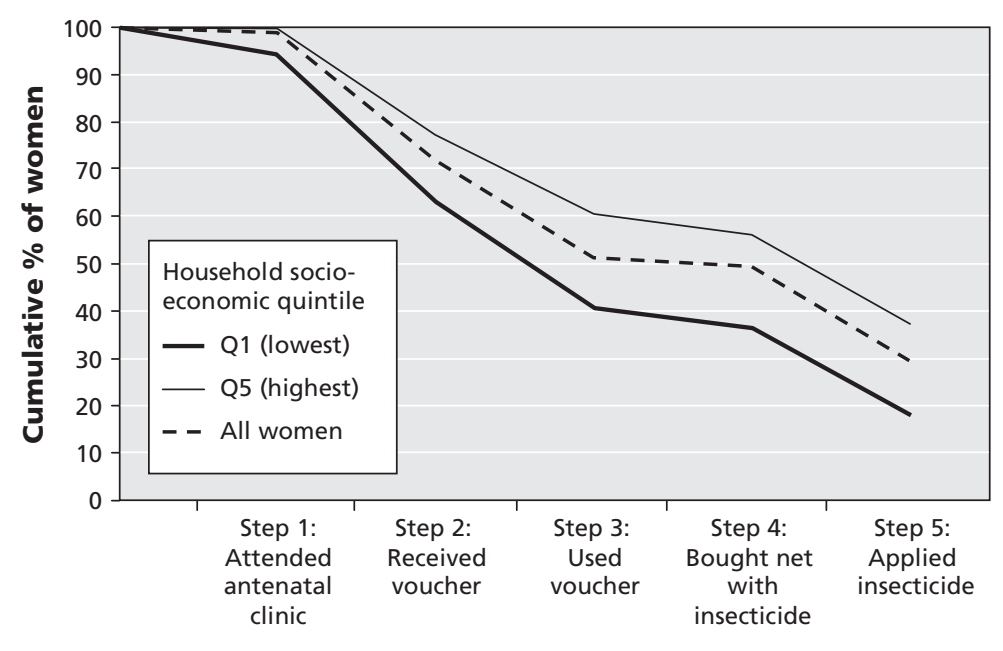

Figure 1: Cumulative success of each step of the Tanzanian National Voucher System for delivering insecticide-treated mosquito nets to pregnant women.

insecticide-treated nets. The first estimate was a predictor of successful delivery of the intervention and reflects the experiences of women who were pregnant in the recent past. The rate of coverage for use of insecticide-treated nets is a measure of the personal use of the intervention by women who are currently pregnant and is thus more contemporary and specific. However, by quantifying the success of each step and evaluating it through the lens of equity, ${ }^{19}$ the analysis of the process affords an opportunity to identify where changes could be made to affect overall coverage and equity. This method has previously been described as a potentially important tool to directly link the processes of a health system with expanding the scale of interventions. ${ }^{20,21}$

Effective and equitable systems of delivery of insecticide-treated nets need both "catch up" strategies that would dramatically increase coverage, and "keep up" strategies that would provide continuous access. ${ }^{22}$ To date, the Tanzanian scheme has

women, from $37 \%$ to $61 \%$ for the richest and from $30 \%$ to $52 \%$ overall, with concomitant improvement in the equity ratio from 0.48 to 0.67 .

\section{Interpretation}

Our analysis of the Tanzanian voucher system shows the challenges of implementing a program aimed at universal coverage on a national scale. The system appeared to function well and reached over two-thirds of the target group of pregnant women at each step. However, because of cumulative attrition across the steps - with each small failure of the process resulting in women dropping out of the system only $30 \%$ of pregnant women interviewed in the 2007 national household survey could be expected to complete the process and benefit from an insecticide-treated net obtained via the voucher system. This attrition was particularly marked for the poorest women, among whom coverage was only $18 \%$, compared with $37 \%$ for the richest.

Personal use of treated nets among currently pregnant women in the 2007 survey was $23 \%$, again with evidence of marked socio-economic inequity as observed for children under five years old ${ }^{14}$ and in other settings. ${ }^{15,16}$ Notably, the analysis of the process predicted a rate of coverage of approximately ten percentage points higher than the actual coverage rate among the poorest participants, and approximately 10 percentage points lower than that among the richest. Two conclusions are suggested by this discrepancy. First, additional barriers to use of an insecticide-treated net may exist, especially among the poor, even after a net has been successfully delivered. These barriers may include inadequate understanding of malaria, misconceptions about the efficacy of treated nets, and differences in number of nets owned relative to household size. ${ }^{17,18}$ Second, richer women may already own nets or have better access than poorer women to nets from other sources.

The estimates derived from the analysis of the process cannot be compared directly with the rate of coverage for use of focused largely on the latter. New plans involve a switch of emphasis toward a catch-up strategy and involve a mass, free delivery of nets treated with long-lasting insecticide to all children under five years old and a mass campaign for retreatment with long-lasting insecticide of all nets used by children in this age group. Alongside this new initiative, options for keep-up strategies for pregnant women must continue to be addressed. ${ }^{23}$ The analysis we present suggests that the single most effective action to increase coverage and reduce inequity would be the delivery of nets treated with long-lasting insecticide.

The Tanzanian National Voucher Scheme is now in its fourth year of nationwide implementation. Although gains in coverage with treated nets have been sustained throughout the period of implementation, the rate of change has been slow and the absolute increase in net coverage has been disappointing. ${ }^{14}$ All delivery-based interventions in this context are vulnerable to constraints in infrastructure and communication that are experienced on a large scale. ${ }^{24} \mathrm{~A}$ disaggregation of systems of delivery may reveal where and why the success of deliverybased interventions is diminished and may be useful for improving coverage among those in greatest need and overall.

\section{This article has been peer reviewed.}

\section{Competing interests: None declared.}

Contributors: Tanya Marchant, David Schellenberg, Joanna ArmstrongSchellenberg and Kara Hanson were involved in the conceptual design of the study and the drafting of the manuscript. Tanya Marchant was involved in the analysis and interpretation of data and wrote the final version of the manuscript. Rose Nathan, Hadji Mponda, Caroline Jones, Yovitha Sedekia and Jane Bruce were involved in the generation of data for the Tanzanian National Voucher Scheme. All of the authors critically reviewed the manuscript for important intellectual content and approved the final version submitted for publication.

Acknowledgements: The authors thank the National Malaria Control Programme and the implementing partners of the Tanzanian National Voucher Scheme, MEDA, Care, World Vision and Population Services International, for their cooperation in the implementation of the study. They also thank Dr. Alex Mwita, Dr. Renata Mandike and Mr. Nick Brown for their commitment to the evaluation process, and Prof. Christian Lengeler and Prof. Don de Sav- 
igny for their valuable comments on an earlier draft of the manuscript. This paper is published with the permission of the Director of the Tanzanian National Institute for Medical Research.

Funding: This work was supported by the Tanzania Ministry of Health and Social Welfare through a combination of grants awarded from the Global Fund to Fight AIDS, TB and Malaria, the Gates Malaria Partnership funded by the Bill and Melinda Gates Foundation, and the United States President's Malaria Initiative.

\section{REFERENCES}

1. Lengeler C, Snow RW. From efficacy to effectiveness: insecticide-treated bednets in Africa. Bull World Health Organ 1996;74:325-32.

2. Bryce J, Victora CG, Habicht JP, et al. Programmatic pathways to child survival: results of a multi-country evaluation of Integrated Management of Childhood Illness. Health Policy Plan 2005;20(Suppl 1):i5-17.

3. Tugwell P, de Savigny D, Hawker G, et al. Applying clinical epidemiological methods to health equity: the equity effectiveness loop. BMJ 2006;332:358-61.

4. Lengeler C. Insecticide-treated bed nets and curtains for preventing malaria [review]. Cochrane Database Syst Rev 2004; (2):CD000363.

5. ter Kuile FO, Terlouw D, Phillips-Howard P, et al. Reduction of malaria during pregnancy by permethrin-treated bed nets in an area of intense perennial malaria transmission in western Kenya. Am J Trop Med Hyg 2003;68(Suppl):50-60.

6. Filmer D. Fever and its treatment among the more and less poor in sub-Saharan Africa. Health Policy Plan 2005;20:337-46.

7. Armstrong Schellenberg JR, Mrisho M, Manzi F, et al. Health and survival of young children in southern Tanzania. BMC Public Health 2008;8:194.

8. World Health Organization. Global strategic plan 2005-2015. Geneva (Switzerland): The Organization; 2005. Available: www.rollbackmalaria.org/forumV/docs /gsp_en.pdf (accessed 2009 Oct. 28).

9. Noor AM, Mutheu JJ, Tatem AJ, et al. Insecticide-treated net coverage in Africa: mapping progress in 2000-07. Lancet 2009;373:58-67.

10. Country profile: Tanzania. Washington (DC): World Bank; 2007. Available: http:/ /ddp-ext.worldbank.org/ext/ddpreports/ViewSharedReport?\&CF=\&REPORT_ID= 9147\&REQUEST_TYPE=VIEWADVANCED (accessed 2009 Oct. 28).

11. Hanson K, Nathan R, Marchant T, et al. Vouchers for scaling up insecticide-treated nets in Tanzania: methods for monitoring and evaluation of a national health system intervention. BMC Public Health 2008;8:205.

12. Filmer D, Pritchett L. Estimating wealth effects without expenditure data — or tears: an application to educational enrollments in states of India. Demography 2001;38:115-32

13. Schellenberg JA, Victora CG, Mushi A, et al. Inequities among the very poor: health care for children in rural southern Tanzania. Lancet 2003;361:561-6.

14. Hanson K, Marchant T., Nathan R., et al. Household ownership and use of insecticide treated nets among target groups after implementation of a national voucher programme in the United Republic of Tanzania: plausibility study using three annual cross sectional household surveys. BMJ. 2009;339:b2434.

15. Noor AM, Amin AA, Akhwale WS, et al. Increasing coverage and decreasing inequity in insecticide-treated bed net use among rural Kenyan children. PLoS Med 2007;4:e255.

16. Webster J, Lines J, Bruce J, et al. Which distribution systems reach the poor? Equity of coverage of never treated nets, ever treated nets, and immunization, to reduce child mortality in Africa. Lancet Infect Dis 2005;5:709-17.

17. Nganda RY, Drakeley C, Reyburn H, et al. Knowledge of malaria influences the use of insecticide treated nets but not intermittent presumptive treatment by pregnant women in Tanzania. Malar J 2004;3:42.

18. Eisele TP, Keating J, Littrell M, et al. Assessment of insecticide-treated bednet use among children and pregnant women across 15 countries using standardized national surveys. Am J Trop Med Hyg 2009;80:209-14.

19. Victora CG, Wagstaff A, Schellenberg JA, et al. Applying an equity lens to child health and mortality: more of the same is not enough. Lancet 2003;362:233-41.

20. Lozano R, Soliz P, Gakidou E, et al. Benchmarking of performance of Mexican states with effective coverage. Lancet 2006;368:1729-41.

21. World Health Organization. The partnership for maternal, newborn and child health: marginal budgeting for bottlenecks. Geneva (Switzerland): The Organization; 2009. Available: www.who.int/pmnch/topics/economics/costing_tools/en /index12.html (accessed 2009 Oct. 28).

22. Lengeler C, deSavigny D. Programme diversity is key to the success of insecticidetreated bednets. Lancet 2007;370:1009-10.

23. Marchant T, Hanson K, Nathan R, et al. Gestation: the key to optimal delivery of insecticide treated bednets in pregnancy. Journal of Epidemiology and International Health. Epub 2009 Nov. 5 ahead of print.

24. Health Systems 20/20. Country brief: Tanzania. Bethesda (MD): United States Agency for International Development; 2007. Avaialble: www.healthsystems2020 .org/content/resource/detail/1285/ (accessed 2009 Oct. 28).

Correspondence to: Dr. Tanya Marchant, London School of Hygiene and Tropical Medicine, Keppel Street, London

WC1E7HT,UK; tanya.marchant@lshtm.ac.uk

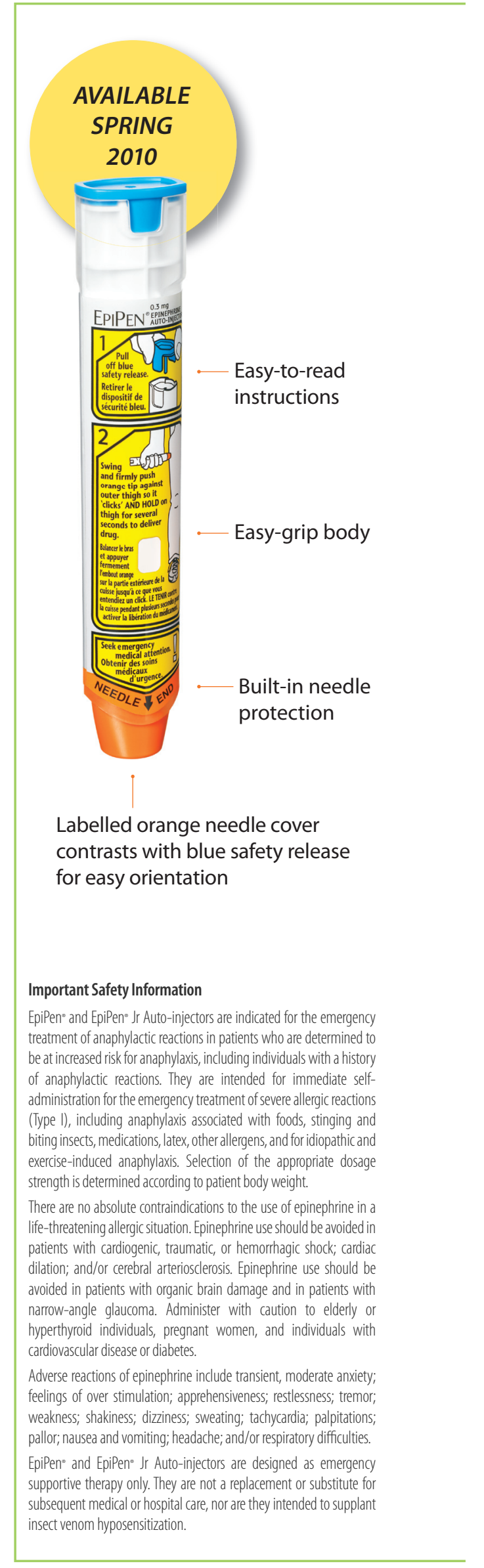

